\title{
EDUCATION
}

\section{Handling the transfer to secondary school}

\section{Elaine Bull}

The transfer to secondary education can be an anxious time and planning ahead can help. This article offers practical advice about what to consider, when to start planning and discusses many of the issues involved in the transition to later schooling. Written from the perspective of the English school system, many of the issues and principles are broadly applicable.

\section{Start early}

Based on personal experience, the transfer to secondary education can be an anxious time and planning ahead can help. My granddaughter is 9 years old and in Year 4 at a local primary school and we have already started looking round the secondary schools. I am aware that the advice usually given to parents is to start this process in Year 5 (see Special Educational Needs Code of Practice - page 57$)^{[1]}$ however, we were advised by the head of the primary school to begin a year earlier and I now know why!

\section{What do you want?}

This is a complicated question to answer and the answers will vary with every child and every family but let me try to help you to think it through. Do you want your child in mainstream secondary education or in a special school? Would you like to consider private education? Look at your child's needs and your view of what you want to get out of a secondary education. Do you want an academic education or a good, well-rounded social education? Has your child any special abilities or interests? Choosing the right school for your child entails striking a balance between what you need, what you want and what is available.

Do you want your child to be included in the school, working with peers or do you want appropriate withdrawal for teaching to meet specific needs? Would you be happy with your child being educated in a unit attached to a school? If so, consider the needs of the pupils within the unit; consider the class size and the staffing ratio. On what occasions are pupils from the unit included in mainstream lessons? How much inclusion takes place? Is it decided upon to meet the needs of the individual child or is it for other reasons?

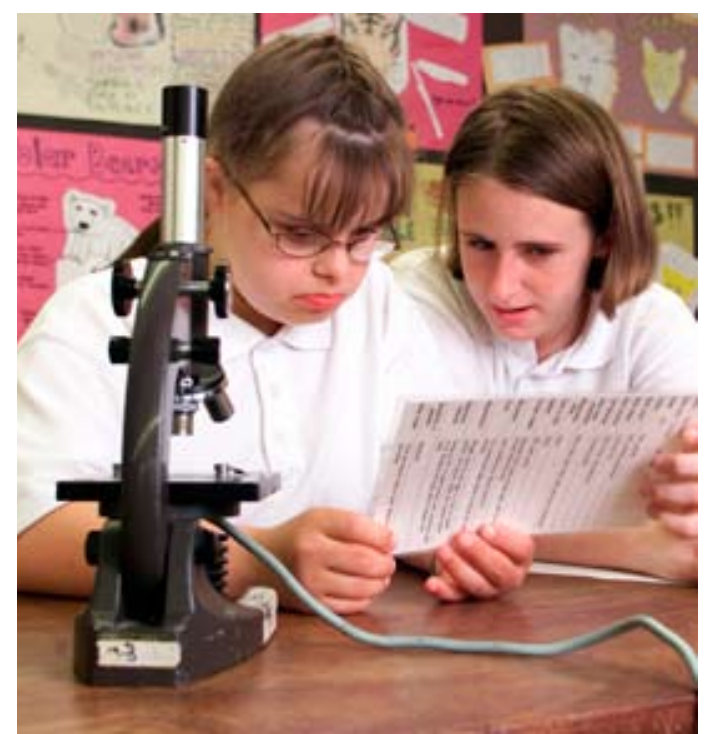

"The transfer to secondary education can be an anxious time. Starting to plan early can help."

\section{Make a list}

By this point, you may want to start a list of your conclusions. What do you really want and what are you willing to compromise on? Your decisions will inform the questions that you will ask when visiting the schools and the answers you will receive will inform your choice of school.

\section{More questions}

Consider your child. This may sound obvious but if your child were to transfer to the same school as the majority of children in the primary setting how many of the peer group would be in the same class? It may be fewer than you think if the secondary school is large. If your child enjoys performing arts, there may be a school that specialises in this area. Does your child need a secure environment? Does your child escape at doi:10.3104/practice.2016

(c) 2007 The Author. Journal Compilation (c) 2008 Down Syndrome Education International. 


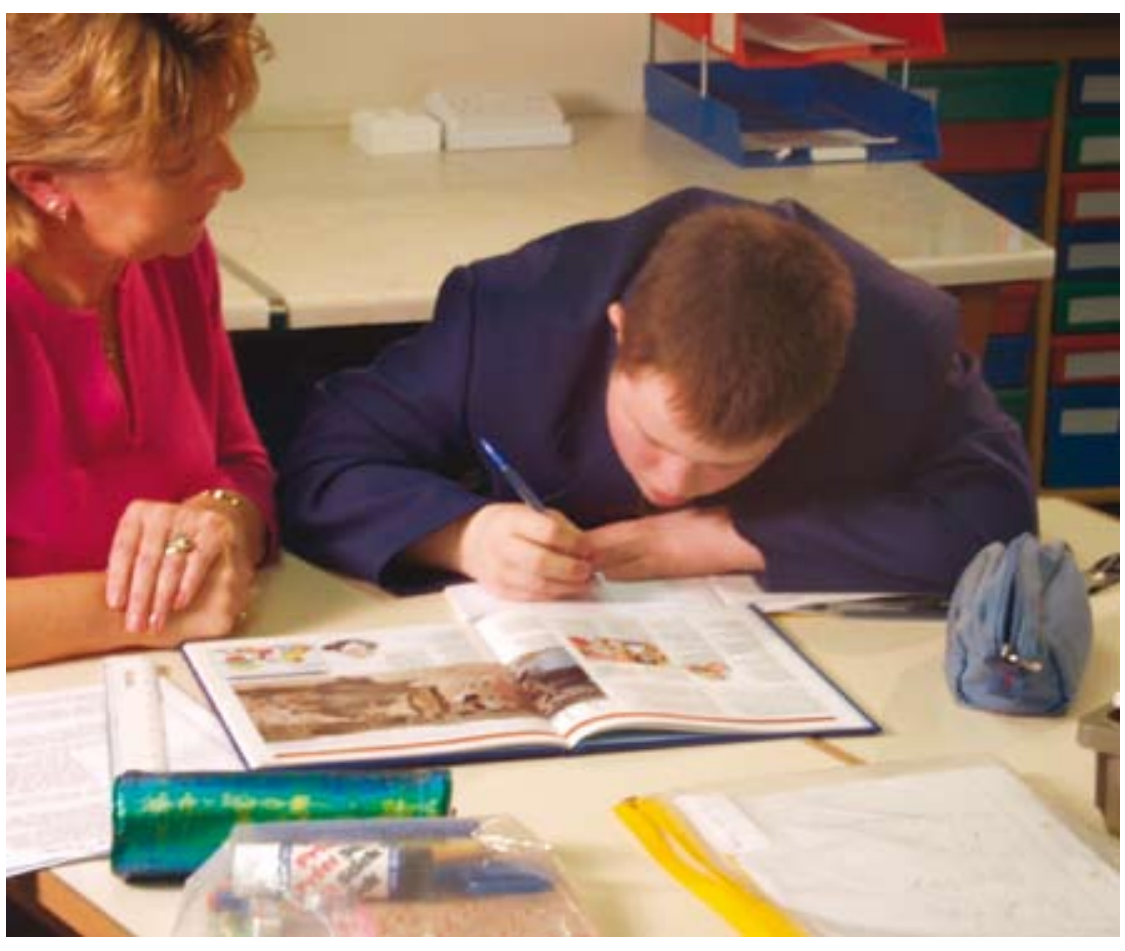

"Do you want your child to be included in the school, working with peers or do you want appropriate withdrawal for teaching to meet specific needs? Would you be happy with your child being educated in a unit attached to a school?"

the first opportunity and have no realisation of the dangers that may follow such behaviour? Can your child communicate effectively or does effective communication depend upon the use of Makaton or another sign system? In which case you will have to ensure that this is used within the school.

How would your child cope with break and lunch times? Is there a base or centre within the school, which is always open and staffed, to which children may retreat at such times if they do not want to go outside? Would it be possible for them to eat their lunch in such a place if the hustle and bustle of the dining-room is too much for them? Could they be withdrawn to such a place for individual or small group teaching when appropriate?

\section{Support and communication}

How does the school use its support staff? Your child may be used to individual support from one Teaching Assistant (TA) - this may not be the practice in a secondary school. The secondary school may allocate several TAs to each child with a statement or they may allocate TAs to departments. Support is organised in many different ways within the secondary system.

How will the school communicate with you and how will you communicate with the school? Who do you contact if there is a problem or something of which the school should be aware?
Are there a variety of channels of communication used regularly or is the annual review, open evenings and the school report all that is offered? Are notes sent home with the child, are home/ school books used, will someone ring if there is an issue and if so, who is it likely to be?

With regard to communication, my daughter has expressed that as a parent you want to know everything which is happening at school. In the 'junior' years, you need to know less than the infant years and by the time children reach secondary school one hopes that this 'need to know' will decline further still, as your child becomes more independent.

As a teacher, a mother and a grandmother of a child with a SEN (Special Educational Needs) I can understand her feelings entirely, but from a practical point of view, as a teacher, my opinion is slightly different. The 'need to know' was expressed to me by an educational psychologist in our area as follows: if it is an issue that the school would usually deal with without informing the parent, there is no need to inform the parents of a child who has the SEN label.

\section{You are almost ready to visit the schools!}

By now you should have thought through the issues and have your list of questions.

I suggest that you discuss these issues with the SENCo (Special Educational Needs Coordinator). You will be visiting the schools with the parents of children in the current Year 6. You do not need to take your child with you at this point, but you do need to know the details of your statement, if you have one.

\section{Your initial visit}

Take note of how the school 'feels' when you visit. What does your 'gut instinct' tell you? One of the schools which my daughter liked, I visited about three years ago and instantly felt that it was a 'happy' school where perhaps my granddaughter might eventually fit in. Does the school feel welcoming?

You may be shown around the school by existing pupils, use this opportunity to talk to your guides. You may know members of staff, or parents of pupils, talk to them all. Talk to the headteacher of your child's primary school, they cannot recommend a school but they will often give you very useful advice. Talk to your educational psychologist, they know your child and the schools.

My daughter and I came up with the following attributes for a SENCo: enthusiastic, excited at the prospect of having your child at the school, vibrant, welcoming, approachable, empathetic, 
a problem solver, willing to listen and not over protective. We also agreed that the school has to be inclusive, that all the staff should be aware of the child, their needs and any potential problems. There should also be a willingness to share knowledge and expertise, to enable everyone to contribute to managing any issues which arise.

Make an initial visit to all the schools in your area armed with your list of questions. Visit the special school, even though this may not be the type of education which you feel appropriate. After your initial visit discuss your findings with the primary head if they are willing. You may find it necessary to make more than one visit to several schools. Make sure that you visit again when the school is in session. The schools which you are considering should make you feel welcome to visit as many times as is necessary for you to be as sure as possible that you are making the correct choice. Take someone with you, perhaps the parent of a child who has similar problems, perhaps a friend who works in special needs, anyone who you can think of who may be willing and able to help. A second person may bring a new perspective to what you are seeing and being told and it is always good to have someone to 'bounce your ideas off'.

You will be able to register your preferred school with the LEA in Y5 but this is not binding, you are free to change your mind later. The choice of secondary schools is usually made at the beginning of Y6, but registering your choice early makes it possible to ensure a smooth transition. It gives time for the SENCo from the receiving school to visit the primary school for annual reviews, it also gives plenty of time for the child to visit the school to meet the staff and explore the layout. An early start will ensure that you have time to reflect on your choice and that there will be the time to prepare for a smooth transition. For more information, see the Code of Practice for SEN section 5/72 $2^{[1]}$.

\section{Visiting the school}

My daughter went armed with the list of issues that she wanted to raise with the Special Needs Co-ordinator (SENCo). Possibly the most important amongst these was the issue of security; my granddaughter Megan is a child who, if not closely supervised, will vanish. A second issue is her difficulty with communication; she has oral dyspraxia and still depends upon signing if she is having difficulty expressing her thoughts. Amongst the remaining issues were encouraging her independence, support and home/school communication.

Five schools were visited, all mainstream secondary whose number of pupils varied between

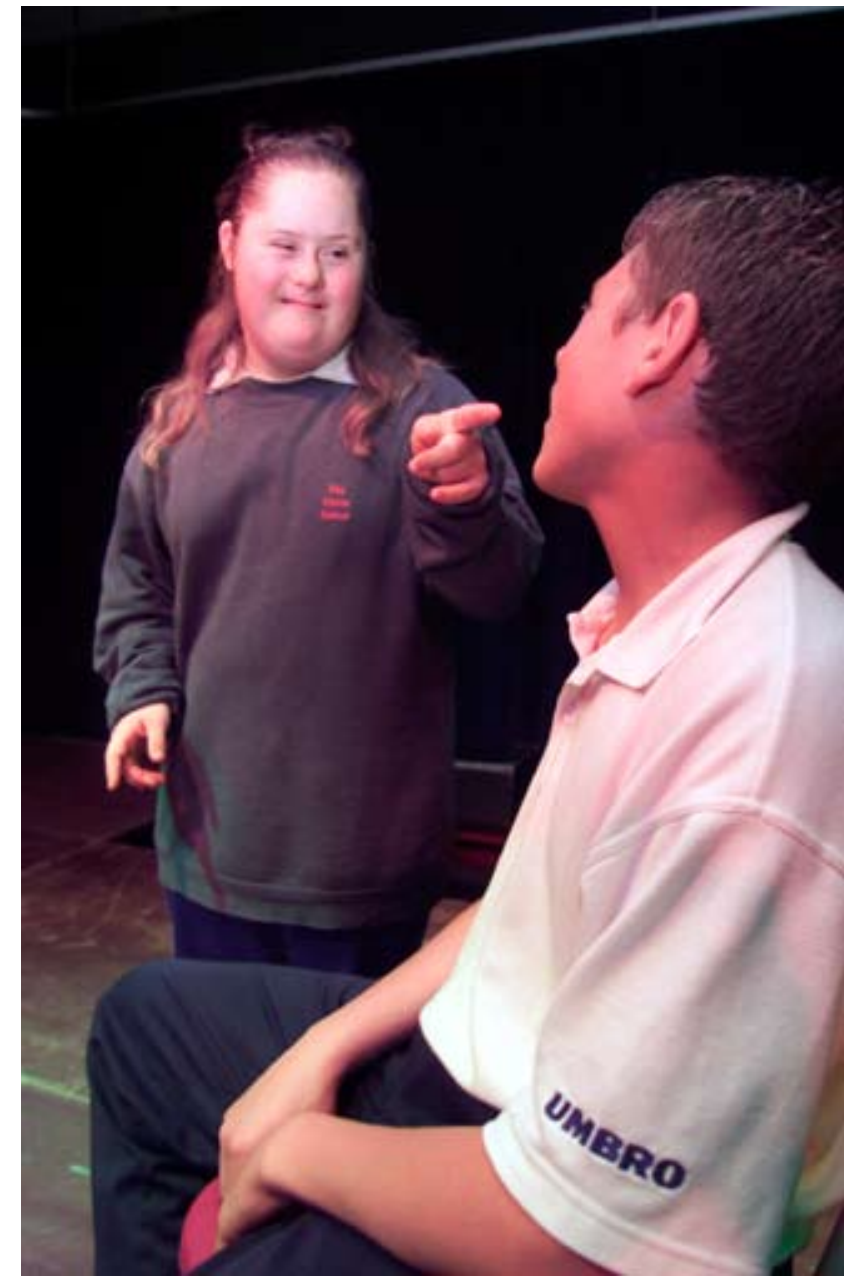

"Do you want an academic education or a good, well-rounded social education? Has your child any special abilities or interests?"

500 and 1200 . What follows is a short account of the replies which were given by the SENCos and information gathered from talking to teachers, pupils and parents.

The smallest school had only one exit which was covered by CCTV. A member of staff monitored children who had a history of escaping, at break times. Movement within the school was based on using a 'buddy system,' but a Teaching Assistant would follow, at a distance, when moving from one side of the school to the other. All staff knew of the children, their needs and issues which may arise. Support was available within each class, and there was one key TA for each child who was statemented; this TA was responsible for the paperwork for the child. School Based Addition Tuition (SBAT) was available as they had their own full time, specialist teacher.

A visual timetable was given to the child, and communication on issues arising during the school day were discussed with the parents by phone. The aim of their support was to encourage independence and encourage the child to seek assistance when needed. At a later date it was discovered that this school is to be rebuilt on a nearby site. The new school will take in half of the pupils from a local secondary, which is to be closed, thereby almost doubling the intake. We 
were made to feel welcome, and encouraged to revisit the school, when it was in session, on as many occasions as we felt was necessary.

At the second school, which was one of the largest schools, the children with SEN were taught in a separate unit. They joined their own class for registration, $\mathrm{PE}$ and Personal and Social Education. It was admitted that they had "never had a child who was so disabled" and that it would "be a brand new learning curve" for them. We were assured that a TA would set the child a task and then the child would work independently. When asked what would happen if the child could not read worksheets, the reply was that they had never experienced that problem. The support within the unit was one TA to 14 children. A SBAT teacher was employed to teach English and Maths to groups in Year 8. We were assured that children do not escape from the school.

When asked if it would be possible to arrange additional visits to the school for the child we were told that this had never happened. The one visit with the primary school was sufficient, and the SENCo asked if we were asking for additional visits because the child was shy. The meeting closed at this point.

Things can only get better, or can they? The third school was a split site and children and staff walked from one site to the other through the middle of town. A result of this was that there was a reduction of staff on site at break times and lunch times, and the school day was extended. There was no form of security, such as CCTV, and the pupils had access to the car park and the main road outside the school.

The unprofessional behaviour of the SENCo, who kept doing impressions of other SENCos in the local schools, and who obviously was more

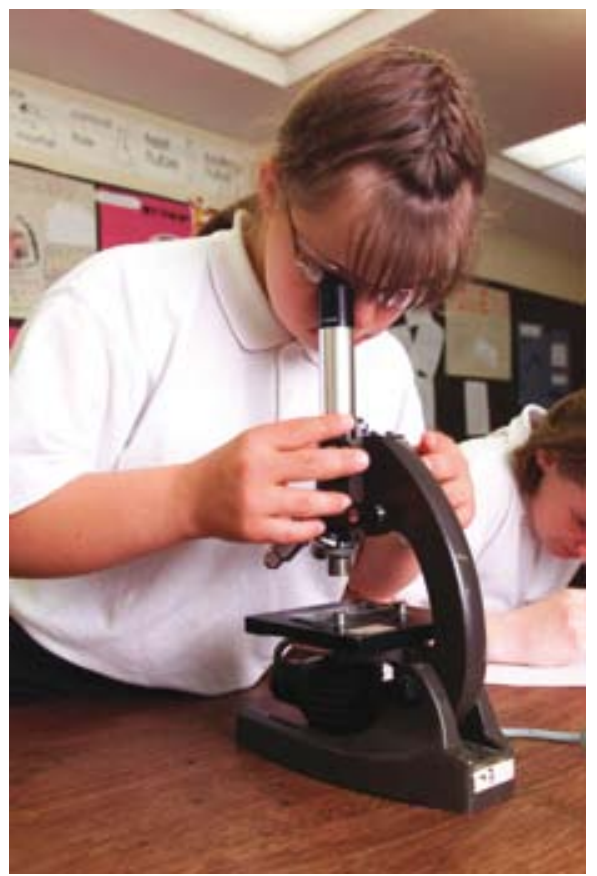

interested in discussing the other schools which we had visited, left us with a negative impression.

The next school had an equally odd SENCo, who considered that the main "selling feature" of the school was the heating system and the lack of draughts. When asked about support we were told that we could have whatever we wanted. When enquiring about an IEP, we could also have one if we wanted. The school had $50 \%$ of the pupils on the SEN register and there was not a learning support base. The SENCo could envisage no problems in having our grand daughter in the school as she was "extremely experienced with special needs." Extra visits to the school could be arranged, and the TA from the primary school could accompany our grand daughter to show her round. It did occur to us that the primary TA might not know the school.

By this point disbelief and despair were beginning to set in, but the final school restored some belief in the possibility of finding a suitable school. This was one of the larger schools, but had a safe base where the pupils could go at break times or lunch times. It could even be arranged that they could have their lunch in the base. The base was open throughout the school day to be used as and when needed.

Three TAs would be allocated to each child and would work on a rota. Children would be taken to reception on arrival at school, and would be collected from there by a TA who would accompany them to the base. Spot checks were made on children who were 'known' escapees and everyone would be informed of their 'habit' to ensure their security. If the child chose to go outside at lunchtime support would be allocated.

The SENCo would attend the annual review in Year 5 and Year 6, whereas all other SENCos had indicated that they would attend the Y6 review. The SENCo would visit the primary school in Y6 to talk to the SENCo and the class teacher, but not to the TA, as it was felt that a 'clean break' was desirable. As many visits as were needed would be arranged for the child. On the first visit, a TA would take the child around the school and they would use a digital camera to help make a visual map of the school and a book. Parents were welcome to go to the school, when it was in session, as often as they wished.

Forms of communication would be discussed at a later date and a package would be designed to meet the requirements for each child. All forms of communication would be considered. As with one other school it was emphasised that the aim was to make the child independent.

Following these visits and prolonged discussions with my daughter, it was agreed that in 
the summer term we would both visit two of the schools, when they were in session. My daughter has also decided to visit the special school, but we have been told that they use one of the schools, that we have rejected, as a link school. The other option, which is still to be explored, is private education. All we need to do next is to work out what issues we have not yet covered!

\section{The decision}

For those of you who have been following the ongoing tale of finding a suitable secondary school for our grand daughter we have good news, we have succeeded - well almost!

Initially my daughter and her husband visited five schools and later visited the special school and re-visited the local secondary school. When visiting the special school we were advised to look for a child whose needs resembled those of our grand daughter and then if we could not find one to talk to the head of the school. There was not a child in the special school who remotely resembled our grand daughter when we considered her needs. When this was discussed with the head of the school he stated that he thought that she should be in a mainstream school.

My daughter re-visited the local secondary as she had been advised that she had painted an 'unrealistic picture' which was taken from the information which the school had supplied. Apparently she was not on P levels for everything as we believed. An appointment was booked and my daughter visited the SENCo for the second time. She asked the same questions and much to our surprise was given completely different answers, more positive answers, answers more in line with what we had hope for on the initial visit. However it was reiterated that the school had never had a child with Down syndrome and that it would be a learning curve for them.

The decision, after much discussion, was that it was not the best school to meet our child's needs and the recent Ofsted inspection which had highlighted special needs did nothing to raise our confidence. Things were going to change but we were not willing to put her education in the hands of a school which would be in the process of change and would be learning about Down syndrome through the inclusion of our grand daughter. We felt that it would be a re-run of the learning curve which her primary school experienced and was continuing to go through. None of us had the energy to start again.

We finally chose the two schools which had impressed us the most and took up their invitations to visit the schools whilst they were in session. As I had had all my questions answered in the initial visit I began to panic about what I was

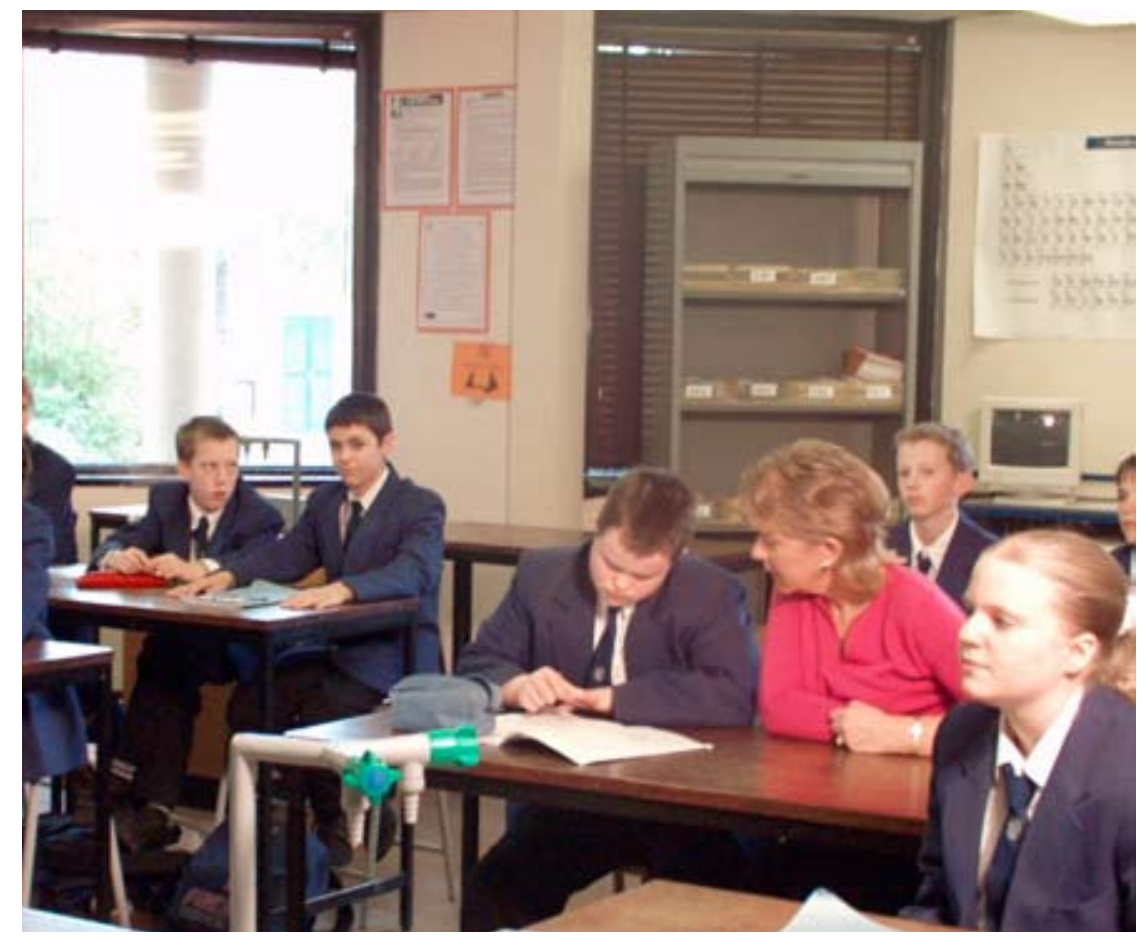

"How does the school use its support staff? Your child may be used to individual support from one Teaching Assistant - this may not be the practice in a secondary school."

looking for. As a teacher who had worked as a SENCo for a number of years and who had also worked with several children who had Down syndrome, as well as teaching dyslexics and working as a befriender for the British Dyslexia Association I felt at a loss; this, after all, was my grand daughter and my daughter was relying on my help and advice.

Fortunately a friend who is an Educational Psychologist was persuaded to join us on the visit. Another pair of eyes and ears and more importantly to me someone who had much more experience of schools working with SEN. We were welcomed to the school by the SENCo who took us around the school explaining things as we discussed the issues and questions arose. We eventually went into the SEN base where several students were working. I immediately felt at home and sat with a small group who with prompts from their teacher explained what they were doing. At the end of the lesson the teacher joined in our discussion. All our questions were answered with honesty, all the children we had met and talked to were very positive and polite. During the change over between lessons we were in the corridor and everyone we saw was behaving very sensibly. I was impressed, we were all impressed.

Our main worry was that the school was to be rehoused and that more children were to be included in the intake once the new building was in use. We were shown the plans and it was 
explained to us that the school would expand by increasing the intake once they were in the new school. Although there was no date fixed we knew that there would be time for her to become secure in her surroundings and establish new friends before the new school was opened.

The second school which we visited couldn't have been more different. We were shown into the head teacher's room where the SENCo was waiting. My daughter had already met the SENCo and had been round the school and had been impressed by the school and their attitude. It was an obvious choice for a second visit and we had been encouraged by the invitation to visit whilst the school was in session.

The head teacher welcomed us and launched into his speech the gist of which was that he had a good school with an excellent staff and a very good special needs department, but he thought that our child should go to her local school. We replied that we thought it was too big and did not consider it suitable. He continued to tell us that if he allowed people like us to bring in special needs children the balance of needs and the staff would be disturbed. He stopped short of saying we do not want your child but said it in as many ways as he could think of.

My daughter was becoming more upset by the minute but I was fascinated and only interrupted him once to remark that my understanding was that he did not have the last word as to which children with SEN he would allow into his school and that the LEA and the parents did have some input into the decision. He stopped and then blustered and continued to dig himself into a hole.

As a teacher I could see what were his concerns but as an observer and a professional I was appalled by his tirade. When we had thanked him for his time we continued with the SENCo showing us around the school. The SENCo was obviously embarrassed and tried to reassure us that if we chose the school he would do everything in his power to ensure that she had the best education possible. Again we finished our tour in the SEN base and had a long discussion with the SENCo.

The decision had been made for us. We did not want to impose our child on a school, we wanted them to welcome her. My thoughts on leaving the school were that it was so unfortunate that the head teacher did not understand how to communicate his fears to parents with children who have SEN. He let his school and his staff down.

My grand daughter and her parents visited the school which we had chosen on the open night for the new intake. As they approached the head teacher he dropped to his knees to talk to her and tell her that he knew all about her and he had been hoping to meet her. He then spoke to her parents. Every time they passed the head teacher on their walk around the school he smiled and waved at her. In the SEN base a teacher put Wordshark on the computer and they worked together whilst her parents talked to the SENCo.

The formal application has been sent in. The next step is for us to supply three letters from people supporting our application. We will not know if she has a place until all the children in Year 6 have been allocated their secondary school places but we have been reassured by everyone concerned that there should be no problem. The SENCo from the school was to attend the annual review; unfortunately she was ill, but plans are in place for her to visit the primary school in the near future.

1. Special Educational Needs Code of Practice. Retrieved 20 February, 2006, from http://www.teachernet.gov.uk/docbank/index. cfm?id=3724

Elaine Bull is a teacher and grandparent living in the UK.

Received: 17 January 2007; Accepted 14 February 2007; Published online: 9 August 2007. 